\title{
The group embedded figure and pattern test for cognitive styles of deaf-mute students
}

\author{
Vaula Greennita Kusumawati*, Andriyani \\ Universitas Ahmad Dahlan, Jl. Pramuka, Yogyakarta, Indonesia \\ *Corresponding e-mail: vaula.greennita@gmail.com
}

\begin{abstract}
This research aim is to describe deaf-mute students' cognitive style which seen in the condition of the Group Embedded Figure Test (GEFT). Data was collected through given by GEFT to four deaf-mute students of SLBN 2 Bantul and the data were analyzed through an interactive analysis of the Miles \& Huberman model namely data collection, data reduction, data display, verification or conclusion inferred. From the test results, two students were categorized to Field-Dependent (FD) cognitive style and the other students were categorized to Field-Independent (FI) cognitive style. Students with FD cognitive styles tend to have difficulty focusing on something or analyzing the pattern into different parts. In contrary, students with FI cognitive style are more capable to accept separate parts of an overall pattern and analyzing the pattern into its components.
\end{abstract}

Keywords: deaf-mute students, field-dependent cognitive style, field-independent cognitive style

How to cite: Kusumawati, V. G., \& Andriyani, A. (2020). The group embedded figure and pattern test for cognitive styles of deaf-mute students. International Journal on Education Insight, 1(2), 69-76. DOI: http://dx.doi.org/ijei.v1i2.2769

\section{INTRODUCTION}

Mathematics learning is given at all levels of education so that students can think to logical, critical, analytical, accurate and rigorous, responsible, responsive and never give up problem-solving. This is stated in the Minister of Education and Culture Regulation Number 21 of 2016 related to the standard content of Primary and Secondary Education. According to Stacey, the results of the PISA (Program for International Student Assessment) show that students alone still experience difficulties in the application of concepts to contextual problem solving, including the use of critical and analytical thinking (Andriyani \& Juniati, 2019). With abstract and hierarchical mathematical objects, students learning experiences will be a factor that influences their learning process on new topics (Andriyani \& Maulana, 2019). Moreover, the implementation of learning that emphasizes procedural and monotonous knowledge, so many students consider mathematics a difficult subject (Hartini, et.al., 2016). The achievement of standards according to this Minister of Education and Culture Regulation is certainly not easy because there are many cases of students' learning disabilities in mathematics such as basic operations of a decimal fraction, measurement skills, fraction terminology, multiplication, and integer fractions (McLeod \& Amstrong, 1982).

If students who haven't physiological structure abnormalities experience it, so students with special needs also have this difficulty in learning mathematics such as deaf-mute students who mostly show severe delays in learning mathematics (Nunes, 2020). This causes them to lag than peers with hearing (Gottardis, et al., 2011). 
According to Thompson (2010), deaf-mute students are students who have hearing problems so they don't respond when spoken to, cannot speak clearly, often press their ears, request that information conveyed be repeated, and the ability to speak is very slow. With the limitations they experienced, the student had certain mental problems and a higher level of anxiety than students with hearing. Their anxiety focused on personal, solitary anxiety and bodily syndrome (Yuping, 2000). Besides anxiety, physical abnormalities also result in the learning disabilities of deaf-mute students.

Learning disabilities occur due to cognitive deficits that interfere with their ability to learn concepts or procedures in one or more mathematical domains (Geary, 2004). A cognition has an important role in understanding a person's concept because to understand the concept there are several cognitive processes in students' internal. One of the cognitive processes contained the activity of understanding students' concepts is interpretation. Student interpretation is an explanation that represents student' mental imagery that depends on the relevant knowledge they have (Andriyani, et al., 2018). The relation between cognition and mathematics learning disability is not only about students' cognitive deficits, but also about students' cognitive styles to be able to turn learning disabilities into learning success.

Cognitive style is part of a learning style that describes the behaviour habits relatively fixed in a person in receiving, thinking, solving problems and in storing information (Keefe, 1979). One kind of student cognitive styles is the Field-Dependent (FD) and Field-Independent (FI) cognitive styles. According to Witkin \& Goodenough, students who included to the FD category tend to remember more social information and relationships, and understand problems globally with an overall picture of the given context (Altun \& Cakan, 2006). They find it difficult to focus on aspects of a situation or to analysis patterns into different parts. Whereas students who included to the FI category will be able to separate one element from the context and tend to understand the problem more analytically. They are more receptive to separate parts of the overall pattern and are able to analysis the pattern into its components than the other.

Differences in student cognitive styles in compiling and processing information and its experiences show how they respond to the learning methods that teachers do. Whereas the teacher can adjust the learning method that suits the cognitive style or the way students organize what their seeing, remembering and thinking.

Based on researcher interviews with teachers of seventh grade at exceptional school SLBN 2 Bantul, it is known that deaf-mute students there have different cognitive styles, so the teacher can't generalize a mathematical learning method to be applied for all students. Based on the description above, the aim of this study is to describe the deaf-mute student' cognitive style in learning mathematics.

This research was conducted to describe the cognitive style of deaf-mute students, so the teacher can choose the appropriate mathematics learning method for students according to their cognitive style. Next, the researcher uses the Group Embedded Figure Test (GEFT) to determine the cognitive style of deafmute students who have certain characteristics.

\section{RESEARCH METHOD}

This research was conducted at exceptional school SLBN 2 Bantul, Yogyakarta. This type of research is a descriptive qualitative research. The subjects of this study were four deaf-mute students of seventh grade. The research instrument

IJEI, Vol. 1, No. 2, October 2020, 69-76 
used to collect data was the Group Embedded Figure Test (GEFT) sheet. GEFT is a psychometric test used to classify students' cognitive styles into FD or FI. The GEFT test contains commands to outline simple images in complicated images. GEFT includes three sections. The first section, which is considered as an introduction that consists of seven problems. The other two sections, namely the second and third that each have nine problems. During the test, instructions on the first page are initially read aloud. Students can work on each section within a time limit of 10 minutes, some students who complete the section in shorter time aren't permitted to continue to the next section, all students begin to work simultaneously on each section. Data analysis was performed using interactive analysis that refers to (Miles \& Huberman, 1994) models namely data collection, data reduction, data display, verification or conclusion inferred.

\section{RESULTS AND DISCUSSION}

After test of GEFT was performed on students who are deaf-mute of seventh grade, two students were categorized on FD cognitive style and two students were categorized on FI cognitive style. Students are given problems which are divided into three sections. In the first section, all of four students can solve the problems well because the problems in the first section are simple. Students seem differences experience in problem solving when solve the problems in the second and third sections. The examples of problem in sections two and three that have differences results as like as showed in Figure 1, Figure 2, and Figure 3.

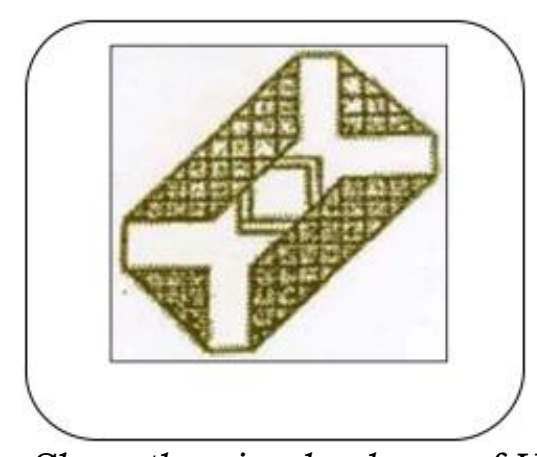

Show the simple shape of $H$

Figure 1. Problem of section two

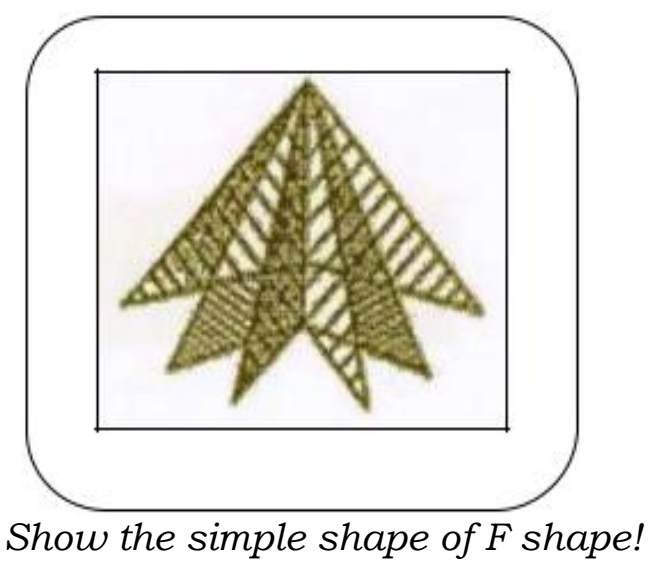

Figure 2. Problem of section three 


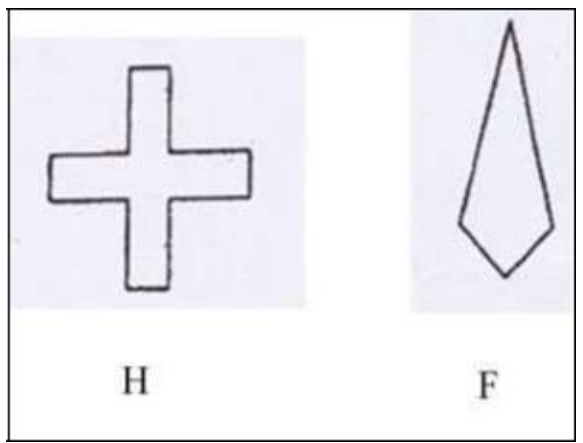

Figure 3. Simple shapes instructed by the problems

Descriptions related to the characteristics of deaf-mute students based on their cognitive style are presented as below.

\section{Field-Dependent (FD) Cognitive Style}

Subjects taken for the FD type were two students who were given the codes R1 and R2. From the results of the GEFT for R1 student with FD cognitive style it is known that R1 student give a thick line to the non-shaded drawing patterns in Figure 1, and the shape is different from the simple shape of $\mathrm{H}$ in Figure 3 as instructed in section two. The solution of R1 student is shown in Figure 4.

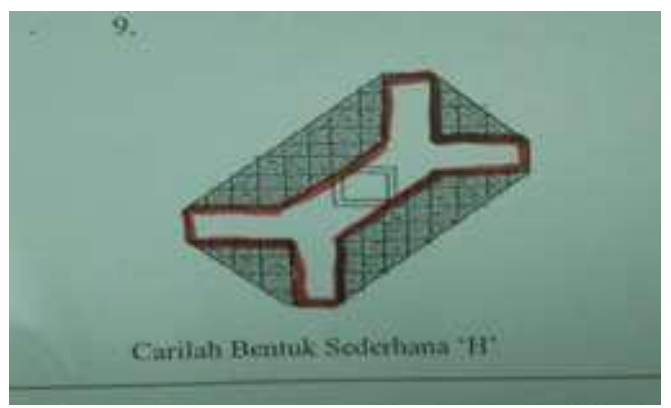

Figure 4. The solving result of $\mathrm{R} 1$ student in section two

In addition, to solve the problems in section two by giving thick lines to the non-shaded drawing pattern, R1 student also made mistakes in giving thick lines to some of the figure in section three because they didn't pay attention the patterns exactly. For example, to make a simple shape of $\mathrm{F}$ as in Figure 3 instructed by problems, R1 student gives a thick line to the third section figure. But the bottom line of the right side and left side of the simple shape of $\mathrm{F}$ that the problem asked to have is made in different length as shown in Figure 5.

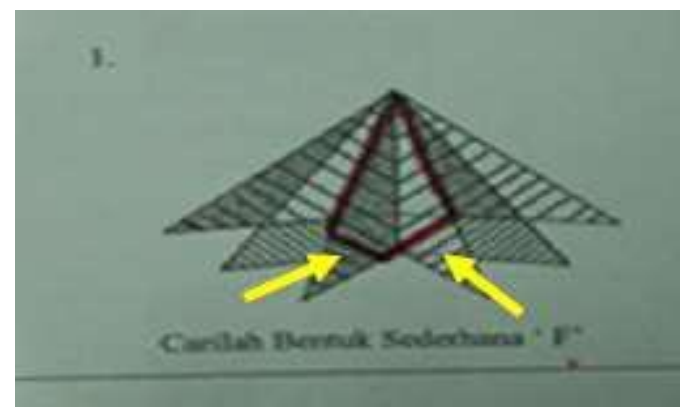

Figure 5. The solving result of $\mathrm{R} 1$ student in section three 
Similar mistakes were also made by R2 student who had the FD cognitive style when giving thick lines to the figure of problems in section two or section three. R2 student give a thick line to the non-shaded drawing patterns in Figure 1 , and the shape is different from the simple shape of $\mathrm{H}$ in Figure 3 as instructed in section two. The R2 student also makes an incomplete shape because he integrates his mental image of the non-shaded drawing pattern in Figure 1 with the simple shape of $\mathrm{H}$ as instructed in section two. Therefore, the solving result of the R2 student shown in Figure 6.

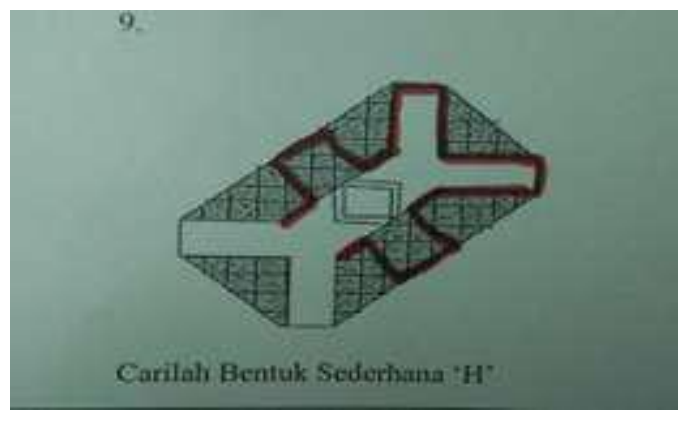

Figure 6. The solving result of R2 student in section two

Although solve the problems in section two by giving thick lines that are incomplete shape to the non-shaded drawing pattern, but R2 student also don't make the same mistakes as R1 student to solve the problem in section three. This can be seen from the similarity in length measurement of the right and left sides of the shape instructed by the problem although the lines are not smooth as shown in Figure 7.

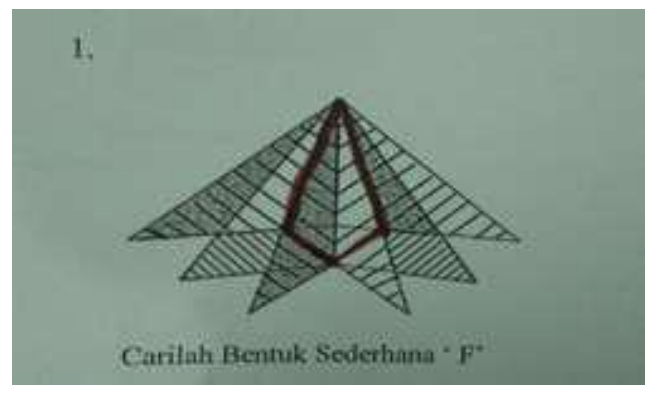

Figure 7. The solving result of R2 student in section three

\section{Field-Independent (FI) Cognitive Style}

Subjects taken for the FI type were two students who were given codes R3 and R4. From the results of the GEFT for R3 student with the FI cognitive style it is known that R3 student give a thick line that similar the simple shape of $\mathrm{H}$ in Figure 3 as instructed in section two. Student R3 makes a simple shape of $H$ on the figure of problem by adding another part to the shaded drawing pattern, after student have given a thick line to the non-shaded drawing pattern in Figure 1. The solving result of R3 student is shown in Figure 8. 


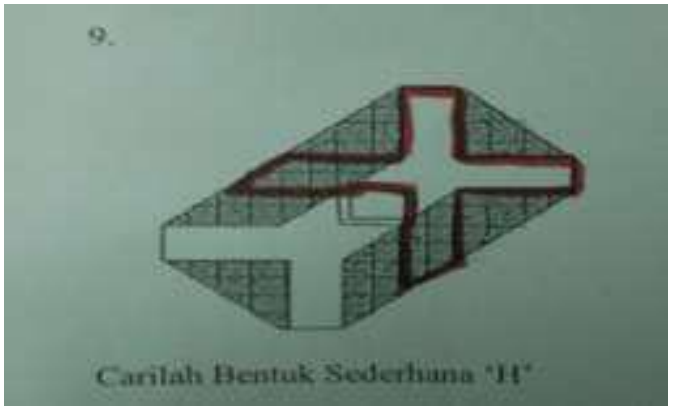

Figure 8. The solving result of R3 student in section two

Besides solving the problems in section two by adding other part to the shaded drawing pattern, R3 student didn't made mistake in solving problems of section three. This can be seen from the solving result when giving a thick line in Figure 1 that represents the simple shape of $F$ according to what he thought. The drawing made by R3 student is also smoother than R2 student. This shows the confidence of R3 student about the similarity of the simple shape which his think with the external representation as shown in Figure 9.

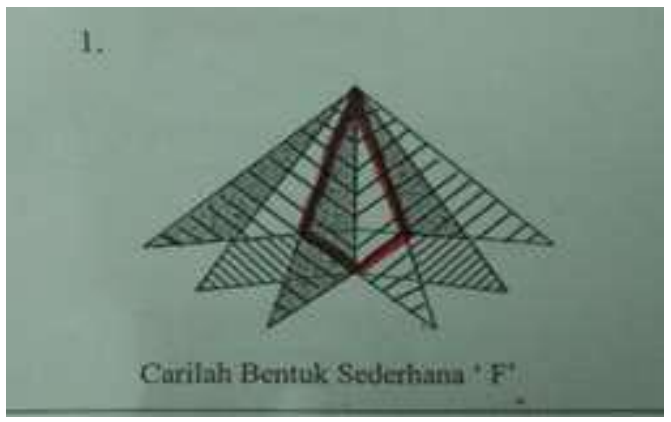

Figure 9. The solving result of R3 student in section three

It same ways is also done by $\mathrm{R} 4$ student who have FI cognitive style when give a thick line in the picture of part two or part three. Student R4 gives a thick line that similar the simple shape of $\mathrm{H}$ in Figure 3 as instructed in section two. Student R4 makes a simple shape of $\mathrm{H}$ on the figure of problem by adding another part to the shaded drawing pattern, after student have given a thick line to the non-shaded drawing pattern in Figure 1. The solving result of R4 student have opposite position 180 degrees from the solving result of R3 student as shown in Figure 10.

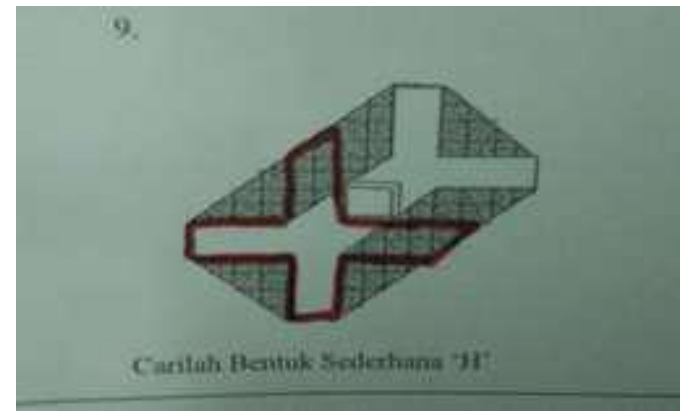

Figure 10. The solving result of $\mathrm{R} 4$ student in section two 
Besides solving the problems in section two by adding other part to the shaded drawing pattern, R4 student is also the same as R3 student who didn't made mistake in solving problems of section three. This can be seen from the solving result when giving a thick line in Figure 1 that represents the simple shape of F according to what he thought. Even the drawing made by R4 student was the same smooth as those of R3 student. This shows R4 students' confidence to the similarity of the simple shape they think about with his external representation.

Based on the analysis of GEFT result data from fourth of deaf-mute students above, it is known that deaf-mute students indicated by the FI style have a more analytical tendency and are able to search for more information beyond the existing content. This can be seen from Figure 8 through Figure 11 which shows that a simple model created by FI style students that has similar shapes with the simple shapes of $\mathrm{H}$ and $\mathrm{F}$. They can distinguish an object from other objects around it and can focus on looking at separate parts of the overall pattern. This means that FI style students are better able to analysis patterns and it components. Whereas FD students still find it difficult to focus on certain aspects of a context or analysis the patterns and it different parts. This shows that the way of FI students approach problems is more global trough an overall figure of the context provided than the part. The characteristics both of cognitive styles are in line with Witkin \& Goodenough statement in Altun and Cakan (2006) and Witkin et al. (1997). Their consistency and belief to their external representation which they're presented through different drawing methods shows that the cognitive style or behavior habits are relatively fixed by each deaf-mute student when given a problem as stated by Keefe (1979) and Schmeck (1988).

Any cognitive style they display is a general or habitual mode of their processing information. This cognitive style needs to be considered in designing learning because cognitive styles influence the learning approach to be used and the learning approach determines the nature of the learning outcome that can change the person including the cognitive style in the time.

Mathematical learning that is not limited by the transmission of facts, skills or mathematical concepts from the teacher to students, clearly needs to pay attention to how the child constructs his/her mathematical knowledge. Therefore, the relation between previous student learning experiences and the concepts to be taught in learning is needed. Moreover, every mathematical concept is related to other concepts and a concept is a prerequisite for other concepts. This is the importance of how to link information or new knowledge received by students with the cognitive style that students have at the learning process.

\section{CONCLUSION}

The differences between students with FD and FI cognitive styles that seen in the ways their external representation it through drawing of shape, it shows the tendency of different behavior patterns. Students with FD cognitive style tend to have difficulty focusing on something or analyzing the pattern into different parts. In contrast, students with FI cognitive style more capable to accept separate parts of an overall pattern and analyzing the pattern into its components. 


\section{ACKNOWLEDGEMENT}

We would like to thank the students and teachers of SLB N 2 Bantul for accepting and allowing us to carry out this research.

\section{REFERENCES}

Altun, A., \& Cakan, M. (2006). Undergraduate students' academic achievement, field dependent/independent cognitive styles and attitude toward computers. Journal of Educational Technology \& Society, 9(1), 289-297.

Andriyani, A., Budayasa, I. K., \& Juniati, D. (2018). The blind student's interpretation of two-dimensional shapes in geometry. Journal of Physics: Conference Series, 947(1), 012055.

Andriyani, A., \& Juniati, D. (2019). The investigation of blind students' misconception in constructing quadrilateral analytic definition using geometry's puzzle. Journal of Physics: Conference Series, 1417(1), 012059.

Andriyani, A., \& Maulana, M. (2019). Cubaritme in the trajectory learning of multiplication concept. Journal of Physics: Conference Series, 1188(1), 012049.

Geary, D. C. (2004). Mathematics and learning disabilities. Journal of learning disabilities, 37(1), 4-15.

Gottardis, L., Nunes, T., \& Lunt, I. (2011). A synthesis of research on deaf and hearing children's mathematical achievement. Deafness \& education international, 13(3), 131-150.

Hartini, S., \& Kesumawati, N. (2015). Desain Pembelajaran materi pengolahan data menggunakan konteks adiwiyata melalui pendekatan PMRI di SD. Numeracy, 2(2), 13-31.

Keefe, J.W. (1979). Student learning style: diagnosing and prescribing programs. Reston. VA: National Association of Secondary School Principals.

McLeod, T. M., \& Armstrong, S. W. (1982). Learning disabilities in mathematics-skill deficits and remedial approaches at the intermediate and secondary level. Learning Disability Quarterly, 5(3), 305-311.

Miles, M. B., \& Huberman, A. M. (1994). Qualitative data analysis 2nd an expanded source book. California: Sage Publication.

Nunes, T. (2020). Deaf children, special needs, and mathematics learning. Encyclopedia of Mathematics Education, 181-183.

Schmeck, R. R. (1988). Perspectives on individual differences: Learning strategies and learning styles. New York: Plenum Press.

Thompson, J. (2010). The essential guide to understanding special educational needs. Harlow: Pearson Education Limited.

Witkin, H. A., Moore, C. A., Goodenough, D. R., \& Cox, P. W. (1977). Fielddependent and field-independent cognitive styles and their educational implications. Review of educational research, 47(1), 1-64.

Yuping, L. (2000). Initial Investigation of Mental Health of Deaf-mute Students [J]. Chinese Journal of Special Education, 4, 003. 